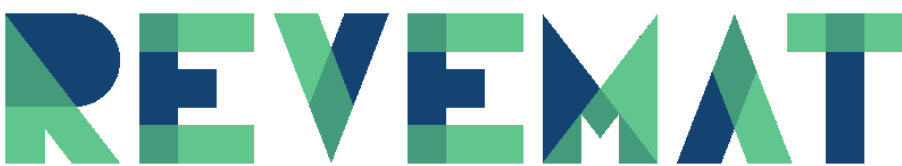

REVISTA ELETRÔNICA DE EDUCAÇÃO MATEMÁTICA

\title{
PRIMEIRA OLIMPÍADA BRASILEIRA DE MATEMÁTICA DOS ANOS INICIAIS - OBMEP: UMA ANÁLISE DOS RESULTADOS OBTIDOS PELOS ALUNOS E DAS PERCEPÇÕES DOS PROFESSORES SOBRE O INSTRUMENTO APLICADO \\ First Brazilian Olympics of Mathematics of the initial years - OBMEP: an analysis of the results obtained by the students and the perceptions of the teachers on the applied instrument
}

Cláudio Cristiano LIELL Faculdade Anhanguera Caxias do Sul, Caxias do Sul, RS, Brasil cristianoliell@hotmail.com Dhttp://orcid.org/0000-0003-1848-7569

Arno BAYER Universidade Luterana do Brasil, Canoas, RS, Brasil bayerarno@yahoo.com.br \http://orcid.org/0000-0001-7721-1162

A lista completa com informações dos autores está no final do artigo

\section{RESUMO}

\begin{abstract}
O presente estudo, parte de uma pesquisa de Pós doutorado, analisa a participação dos estudantes de $4^{\circ}$ e $5^{\circ}$ anos na $1^{\text {a }}$ Olimpíada Brasileira de Matemática das Escolas Públicas - Nível A e as percepções dos seus professores sobre a avaliação aplicada. A pesquisa foi elaborada por meio de respostas oriundas de questionários respondidos por 92 professores e gestores das escolas públicas do Vale dos Sinos, Paranhana e Caí sobre o desempenho dos seus alunos nas provas e a compreensão destes envolvidas sobre o instrumento aplicado. De acordo com resultados obtidos, as questões com maior porcentagem de alunos que cometeram erros, referem-se principalmente aos conteúdos das unidades temáticas de álgebra, grandezas e medidas; para metade dos professores, as questões apresentaram um grau de dificuldade superior das que são trabalhadas em aula; de forma expressiva os educadores apresentam dificuldade de trabalho em sala de aula com questões de Geometria e álgebra e destacam que nas escolas não deixam trabalhar estes conteúdos, porque pedem para priorizar as quatro operações.
\end{abstract}

Palavras-chave: Olimpíadas de matemática, Percepções professores, Desempenho dos alunos.

\section{ABSTRACT}

This study, part of a postdoctoral research, analyzes the participation of 4 th and 5 th grade students the $1^{\text {a }}$ Brazilian Mathematical Olympiad of the Public Schools - Level A and the your teachers' perceptions about the applied evaluation. The research was elaborated through answers from questionnaires answered by 93 teachers and managers of Vale dos Sinos, Paranhana and Caí public schools about the performance of their students in the tests and the understanding of these involved about the applied instrument. According to results obtained, the questions with the highest percentage of students who made mistakes, refer mainly to the contents of the thematic units of algebra, magnitudes and measures; for half of the teachers, the questions presented a degree of difficulty superior to those that are worked in class; in an expressive way the educators present difficulties of work in class with questions of Geometry and algebra and they emphasize that in the schools they do not leave to work these contents, because they ask to prioritize the four operations.

Keywords: Math Olympics, Teacher perceptions, Performance of students. 


\section{INTRODUÇÃO}

Atualmente, percebe-se que muitos estudantes não estão motivados para a aprendizagem de conceitos no dia a dia escolar. Para que ocorra a reversão desse quadro, vários projetos vêm sendo desenvolvidos na escola, como, por exemplo, o desenvolvimento de feiras científicas, a criação de museus e a realização de olimpíadas científicas.

No Brasil, as olimpíadas de conhecimento envolvem milhões de alunos e centenas de milhares de professores. A mais importante é a Olimpíada Brasileira de Matemática das Escolas Públicas - OBMEP, que é um projeto nacional dirigido às escolas públicas e privadas brasileiras, realizado pelo Instituto Nacional de Matemática Pura e Aplicada IMPA, com o apoio da Sociedade Brasileira de Matemática - SBM, e promovida com recursos do Ministério da Educação e do Ministério da Ciência, Tecnologia, Inovações e Comunicações - MCTIC.

O ambiente escolar é um local propício para discussões de conhecimentos e para as inovações dos saberes para o desenvolvimento de desafios. Portanto, propor esses desafios através da OBMEP, pode trazer contribuições significativas para o ensinoaprendizagem da Matemática.

Criada em 2005 para estimular o estudo da matemática pelos alunos, identificar talentos dos educandos na área e contribuir para a melhoria da qualidade da educação básica, a OBMEP tinha, até 2018 , o público-alvo composto de alunos do $6^{\circ}$ ano do Ensino Fundamental até último ano do Ensino Médio. No final de 2018, ela também foi desenvolvida para alunos de $4^{\circ}$ e $5^{\circ}$ ano do Ensino Fundamental regularmente matriculados em escolas públicas municipais, estaduais e federais brasileiras.

Assim, para entender essas contribuições é preciso captar a percepção dos sujeitos sociais diretamente envolvidos com a questão, dentre os quais podem ser listados os professores de matemática e os alunos. Portanto, este artigo realiza um estudo sobre a $1^{\text {a }}$ Olimpíada Brasileira de Matemática das Escolas Públicas - Nível A.e

Com a proposta de analisar a participação dos estudantes nas provas da OBMEP e as percepções dos professores sobre o instrumento aplicado, esse trabalho focará as análises nas respostas oriundas de questionários respondidos pelos professores e pelos gestores das escolas sobre o desempenho dos alunos nas provas e a compreensão destes envolvidas sobre o instrumento aplicado. Será empregado nessa pesquisa um 
questionário com 8 questões abertas e fechadas, cujas respostas de 89 professores e gestores dos anos iniciais serão analisadas quantitativamente e qualitativamente.

\section{AS OLIMPÍADAS DE CONHECIMENTO}

De maneira semelhante às olimpíadas esportivas, as olimpíadas científicas são competições, porém com focos diferentes. Enquanto nas olimpíadas esportivas as habilidades físicas, a princípio, são o foco das competições, nas olimpíadas de conhecimento o objetivo primordial está nas habilidades intelectuais do estudante.

Desde o século XVI, ocorrem desafios nos quais a disputa se dá por meio de competições de conhecimento. Segundo Maciel (2009), desafios entre matemáticos, em que se apostava prestígio, dinheiro e cátedras em universidades, eram práticas comuns. De forma geral, o vencedor era aquele que resolvesse o maior número de problemas e as competições aconteciam sob a forma de duelos.

As competições de conhecimentos, surgiram por volta do ano de 1885 na cidade de Bucareste, na Romênia. Os alunos da escola primária participavam de uma competição de matemática em busca de 11 prêmios, sendo 9 para meninos e 2 para meninas.

Já a expressão "Olimpíada" começou a ser utilizada em competições de conhecimento somente em 1894, com a primeira Olimpíada de Matemática na Hungria, e era direcionada para alunos do último ano da escola secundária, que corresponderia aos alunos do ensino médio brasileiro. (Alves, 2010).

Ainda, conforme Alves (2010), as competições de conhecimentos aos poucos se espalharam pelo leste europeu e pela União Soviética. Esse processo resultou na organização da primeira Olimpíada Internacional de Matemática (IMO2) em 1959, na Romênia, para os alunos correspondentes ao Ensino Médio brasileiro. A partir dessa data, a Olimpíada ocorre anualmente, com exceção do ano de 1980, pois a Olimpíada foi cancelada devido aos conflitos internos na Mongólia (Turner, 1985).

A primeira olimpíada de conhecimento, no Brasil, foi uma competição de Matemática. Para Burigo (1989), as primeiras Olimpíadas de Matemática no Brasil aconteceram em 1967 ao longo do Movimento da Matemática Moderna, no estado de São Paulo, foram organizadas pelo Grupo de Estudo do Ensino da Matemática - GEEM e denominadas Olimpíada de Matemática do Estado de São Paulo - OMESP. Essa 
Olimpíada teve apenas duas edições, uma em 1967 e outra em 1969, dando espaço para a Olimpíada Paulista de Matemática - OPM, que teve sua primeira edição em 1977.

A primeira Olimpíada Brasileira de Matemática - OBM, organizada pela Sociedade Brasileira de Matemática (SBM), ocorreu em 1979. Outras sociedades científicas, a partir de então, iniciaram a organização de suas olimpíadas de conhecimento, tais como a Olimpíada Brasileira de Astronomia (1998) e a Olimpíada Brasileira de Física (1999). Desde então, várias Olimpíadas de Conhecimento surgem no Brasil, oportunizadas por estados e municípios.

\section{OLIMPÍADA BRASILEIRA DE MATEMÁTICA DAS ESCOLAS PÚBLICAS - OBMEP}

A Olimpíada Brasileira de Matemática das Escolas Públicas - OBMEP é um projeto nacional dirigido às escolas públicas e privadas brasileiras, realizado pelo Instituto Nacional de Matemática Pura e Aplicada - IMPA, com o apoio da Sociedade Brasileira de Matemática - SBM, e promovida com recursos do Ministério da Educação e do Ministério da Ciência, Tecnologia, Inovações e Comunicações - MCTIC.

Criada em 2005 para estimular o estudo da matemática e identificar talentos na área, a OBMEP ocorre anualmente em duas fases que são distribuídas em três níveis. $\mathrm{O}$ público-alvo da OBMEP era composto, até 2017, por alunos do $6^{\circ}$ ano ao $9^{\circ}$ ano do Ensino Fundamental e os alunos do Ensino Médio, de Escolas Públicas Municipais, Estaduais e Federais, e Escolas Privadas, bem como os respectivos professores, escolas e secretarias de educação.

Conforme informações obtidas no site da OBMEP, os alunos participantes da OBMEP 2018 foram divididos em 3 (três) níveis, de acordo com o seu grau de escolaridade para a aplicação da olimpíada:

I. Nível 1 - alunos matriculados em 2018 no $6^{\circ}$ ou $7^{\circ}$ ano do Ensino Fundamental. II. Nível 2 - alunos matriculados em 2018 no $8^{\circ}$ ou $9^{\circ}$ ano do Ensino Fundamental. III. Nível 3 - alunos matriculados em 2018 em qualquer ano do Ensino Médio.

Ela é realizada em duas fases, sendo a primeira caracterizada pela aplicação de prova objetiva, de caráter eliminatório, com 20 (vinte) questões de múltipla escolha, diferenciada para os níveis, realizadas nas escolas dos estudantes e corrigidas pelos seus professores que apresentam os gabaritos elaborados pelo IMPA. Já na segunda fase, são classificados apenas os alunos que obtiveram as maiores notas na prova da 
Primeira Fase, e é aplicada uma prova discursiva, de caráter classificatório, diferenciada por níveis. Os locais de realização das provas da Segunda Fase, são definidos pela organização da Olimpíada e geralmente ocorrem em apenas uma escola do município, denominadas de centros de aplicação.

De forma geral, a OBMEP foi desenvolvida para:

- Estimular e promover o estudo da Matemática;

- Contribuir para a melhoria da qualidade da educação básica, possibilitando que um maior número de alunos brasileiros possa ter acesso a material didático de qualidade;

- Identificar jovens talentos e incentivar seu ingresso em universidades, nas áreas científicas e tecnológicas;

- Incentivar o aperfeiçoamento dos professores das escolas públicas, contribuindo para a sua valorização profissional;

- Contribuir para a integração das escolas brasileiras com as universidades públicas, os institutos de pesquisa e com as sociedades científicas;

- Promover a inclusão social por meio da difusão do conhecimento. (OBMEP, 2018, site)

Nas Olimpíadas da OBMEP, são premiados alunos, professores, escolas e secretarias municipais de educação pelos melhores desempenhos em cada edição. Essa premiação baseia-se exclusivamente no resultado das provas da Segunda Fase. Os alunos premiados poderão ter a oportunidade de participar do Programa de Iniciação Científica, receber bolsa de Iniciação Científica Jr do Conselho Nacional de Desenvolvimento Científico e Tecnológico (CNPq) e certificados de Menção Honrosa. As escolas dos alunos premiados podem receber kit pedagógicos e os professores de alunos premiados poderão receber diploma de homenagem e um livro de apoio à formação matemática.

No ano de 2018, a Olimpíada Brasileira de Matemática das Escolas Públicas (OBMEP) ampliou seu alcance. A competição nacional que reunia cerca de 18 milhões de crianças e de jovens se ampliou aos alunos dos $4^{\circ}$ e $5^{\circ}$ anos do Ensino Fundamental de escolas públicas municipais, estaduais e federais. A iniciativa expande o potencial de participantes da OBMEP em mais 5,2 milhões de estudantes de 87 mil unidades de ensino. Com 20 questões objetivas, as provas foram aplicadas em 30 de outubro nas próprias escolas em todo o país.

Da mesma maneira que a competição realizada anualmente desde 2005, a $1^{\text {a }}$ Olimpíada Brasileira de Matemática das Escolas Públicas - Nível A (OBMEP Nível A 2018) apresentou como objetivo estimular o estudo da Matemática, contribuir para a melhoria da qualidade da Educação Básica, identificar jovens talentos e promover a 
inclusão social. Os organizadores acreditam que a olimpíada pode evitar que os estudantes dos anos iniciais percam o gosto pela matemática, que é mais intenso e aguçado nessa fase de desenvolvimento da criança.

\section{METODOLOGIA}

O Estado do Rio Grande do Sul apresenta uma rede de ensino com aproximadamente 840.000 alunos, distribuídos em 2497 estabelecimentos de ensino, orientados e auxiliados por 30 Coordenadorias de Educação.

Os professores dos $4^{\circ}$ e $5^{\circ}$ anos dos anos iniciais do Ensino Fundamental das escolas estaduais do Vale do Sinos, do Caí e do Paranhana, foram os indivíduos investigados nesse estudo. Foram envolvidos 92 educadores, dos 39 municípios que compõe essas regiões do Estado do Rio Grande do Sul.

O Quadro 01 traz dados referentes às regiões investigadas em comparação aos do Estado do Rio Grande do Sul:

Quadro 01 - Dados do Estado do RS e Vales do Caí, do Sinos e do Paranhana

\begin{tabular}{|c|c|c|c|c|}
\hline Nível & População & $\begin{array}{c}\text { Professores } \\
\text { Regentes de Classe } \\
\text { do } \mathbf{4}^{\circ} \mathbf{e} \mathbf{5}^{\circ} \text { anos }\end{array}$ & Alunos & $\begin{array}{c}\text { Escolas } \\
\text { Estaduais }\end{array}$ \\
\hline $\begin{array}{c}\text { Vale do Sinos, do Caí e } \\
\text { do Paranhana }\end{array}$ & 1.701 .580 & 2.851 & 70.217 & 164 \\
$\begin{array}{c}\text { Estado do Rio Grande do } \\
\text { Sul }\end{array}$ & 11.329 .605 & 44.094 & 895.268 & 2.497 \\
\hline
\end{tabular}

Fonte: $2^{\mathrm{a}}$ Coordenadoria de Educação/maio 2018.

Para a construção das análises e das discussões a respeito do tema investigado, as escolas responderam a um questionário com 5 questões fechadas e 4 questões abertas que foram respondidas oralmente (em forma de entrevista) ou por escrito pelos professores dos anos iniciais das regiões citadas.

Os dados foram analisados por meio da abordagem metodológica quantiqualitativa, que se justifica na medida em que utilizam as características de ambos os enfoques no estudo realizado. Moreira e Caleffe definem a pesquisa qualitativa e quantitativa como: 
A pesquisa qualitativa explora as características dos indivíduos e cenários que não podem ser descritos numericamente. $O$ dado é frequentemente verbal e é coletado pela observação, descrição e gravação. A pesquisa quantitativa, por outro lado, explora as características e situações de que dados numéricos podem ser obtidos e faz uso da mensuração e estatísticas. Ambas podem ser usadas no mesmo estudo (Moreira \& Calefe, 2008, p. 73).

\section{RESULTADOS E ANÁLISES}

Os dados obtidos para a elaboração das análises foram extraídos da aplicação de questionários a 89 professores sobre a $1^{\text {a }}$ Olimpíada Brasileira de Matemática das Escolas Públicas - Nível A, aplicada aos estudantes do $4^{\circ}$ ano. A seguir, são apresentadas as conclusões que foram obtidas com 0 instrumento investigativo, respondido pelos educadores.

De acordo com a Figura 01, que apresenta a formação dos 92 entrevistados, dentifica-se que $72 \%$ dos entrevistados tem formação superior em Pedagogia, sendo que $50 \%$ desses tem especialização e apenas $9 \%$ apresenta curso de Magistério, nível médio.

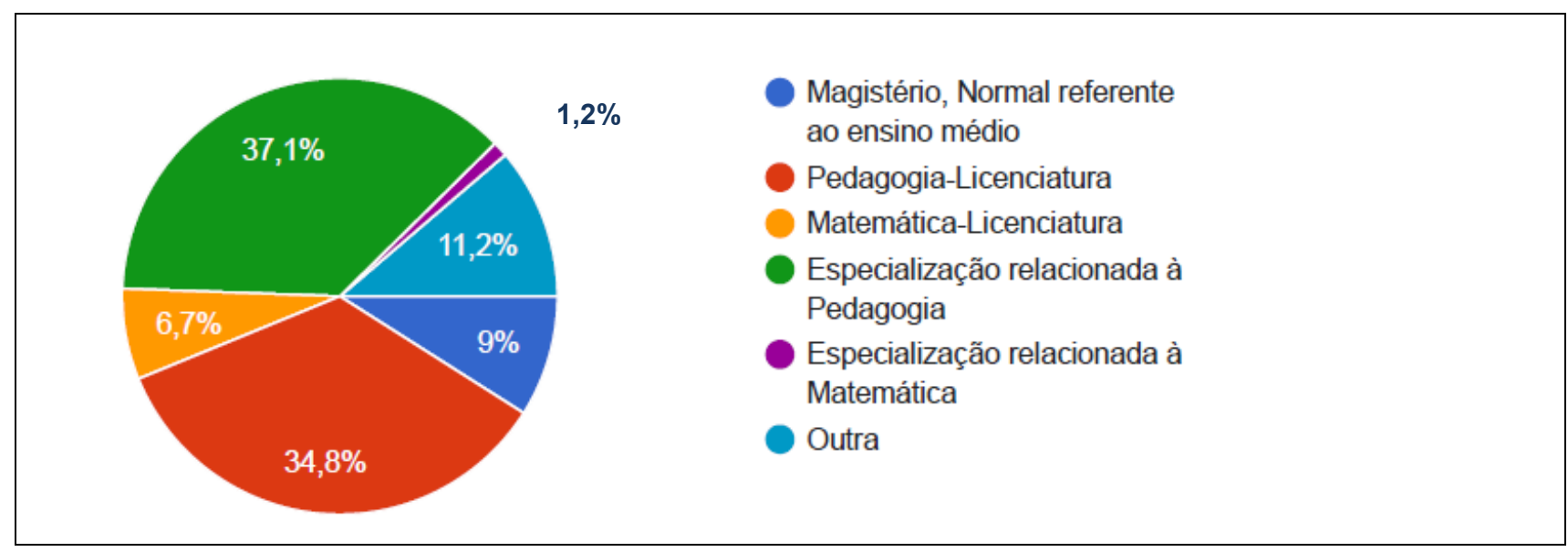

Figura 1: Formação dos entrevistados

Fonte: A pesquisa

Quando questionados sobre o nível de dificuldade da $1^{\text {a }}$ Olimpíada Brasileira de Matemática das Escolas Públicas - Nível A, os resultados obtidos são indicados na Figura 02. 


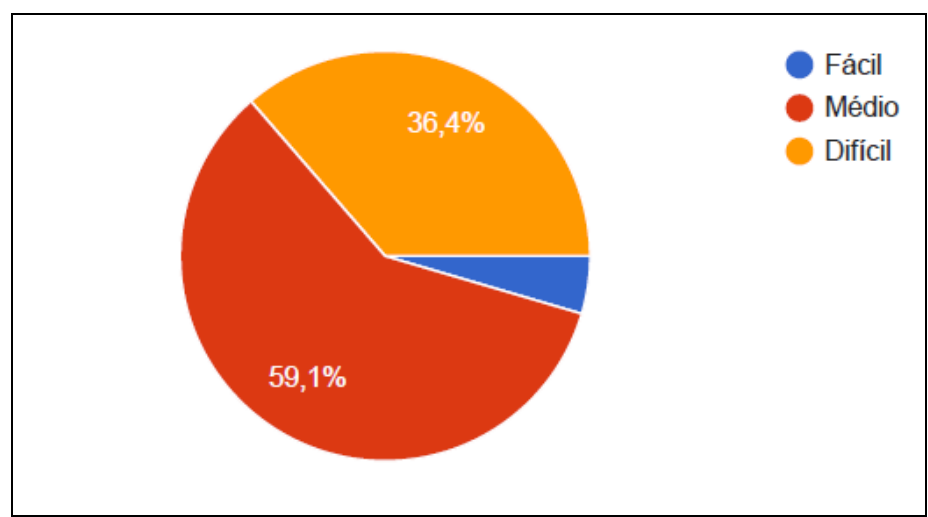

Figura 2: nível de dificuldade Fonte: A pesquisa

Para 59\% dos educadores, avaliação foi considerada de nível médio e um fato a ser considerado é que as olimpíadas necessitam ser desafiadoras para estimular os estudantes para que resolvam com dedicação as questões desse instrumento, porém é necessário que sejam adequadas didaticamente e, também, no nível cognitivo dos alunos, não sendo uma simples forma de cobrança de conteúdo, mas também uma forma de construção de conceitos, que envolvam os professores e alunos.

A figura 03, apresenta a porcentagem de acertos dos alunos em cada uma das 20 questões da Olimpíada.

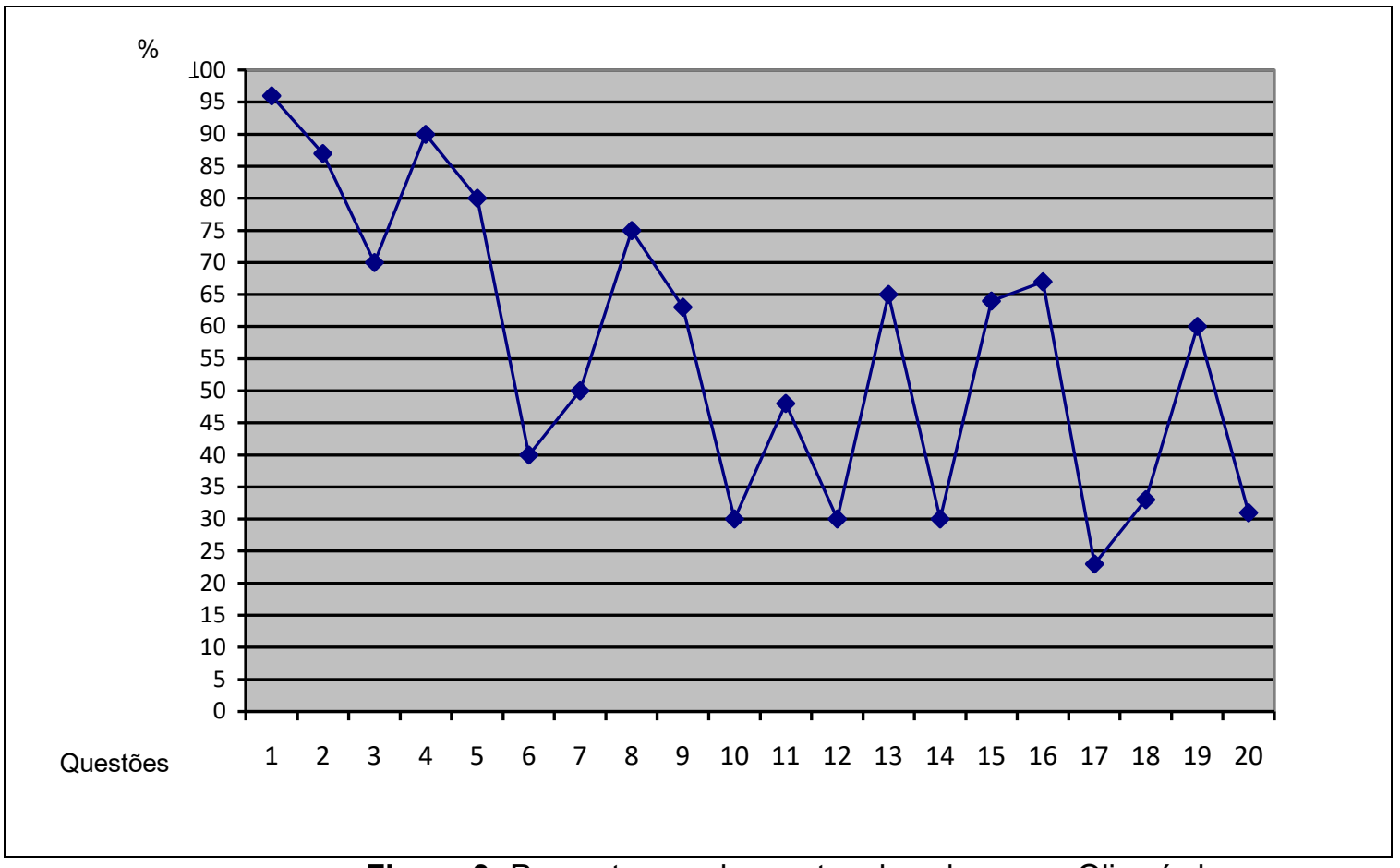

Figura 3: Porcentagem de acertos dos alunos na Olimpíada Fonte: A pesquisa 
Sudbrack e Cocco (2013), consideram que a OBMEP pode ser considerada como uma avaliação de larga escala, pois pode servir como indicador da qualidade educativa na área de Matemática.

Observa-se que as questões $6,10,11,12,14,17,18$ e 20 não foram realizadas corretamente por nem 50\% dos alunos, sendo que nas questões 12, 14, 17 e 20 o índice de acertos foi mínimo. Já as questões 1, 2, 3, 4, 5 e 8 foram as questões com maior número de acertos, ou seja, foram resolvidas corretamente por mais de $70 \%$ dos estudantes. As questões com maior porcentagem de alunos que cometeram erros, referem-se principalmente aos conteúdos das unidades temáticas de álgebra, de grandezas e de medidas.

Conforme Pavanello, Lopes e Araújo (2011), uma das dificuldades que pode ser percebida durante a realização da Olimpíada, refere-se à leitura e à interpretação de enunciados de problemas matemáticos. Portanto, se faz necessário um trabalho intenso visando ampliar o domínio de interpretação dos alunos, que vai além da leitura em Língua Portuguesa, pois a língua matemática é permeada de símbolos e de significados, próprios da matemática e, algumas vezes, diferentes daqueles usados no cotidiano.

Foi solicitado aos professores que respondessem em quais as unidades temáticas ${ }^{1}$ presentes nas questões da olimpíada que os alunos apresentaram maior dificuldade de resolução. Os resultados podem ser observados na Figura 4.

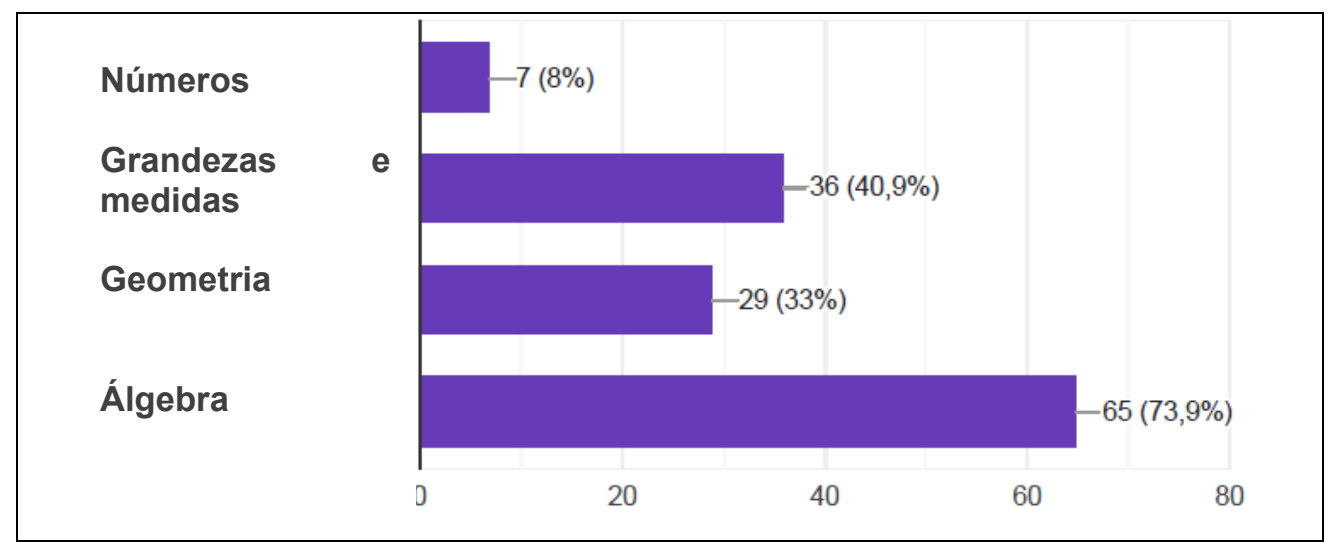

Figura 4: Unidades temáticas que os alunos apresentaram dificuldades de resolver Fonte: A pesquisa

De acordo com os dados apontados na figura 04 pelos professores, é possível perceber que eles conferem com os resultados observados nos testes. A Figura 05 traz os

\footnotetext{
1 Unidades temáticas do ensino fundamental em matemática, segundo a BNCC: Números, Grandezas e medidas, Geometria e álgebra
} 
motivos apontados pelos educadores entrevistados a respeito das dificuldades de resolução das questões pelos estudantes.

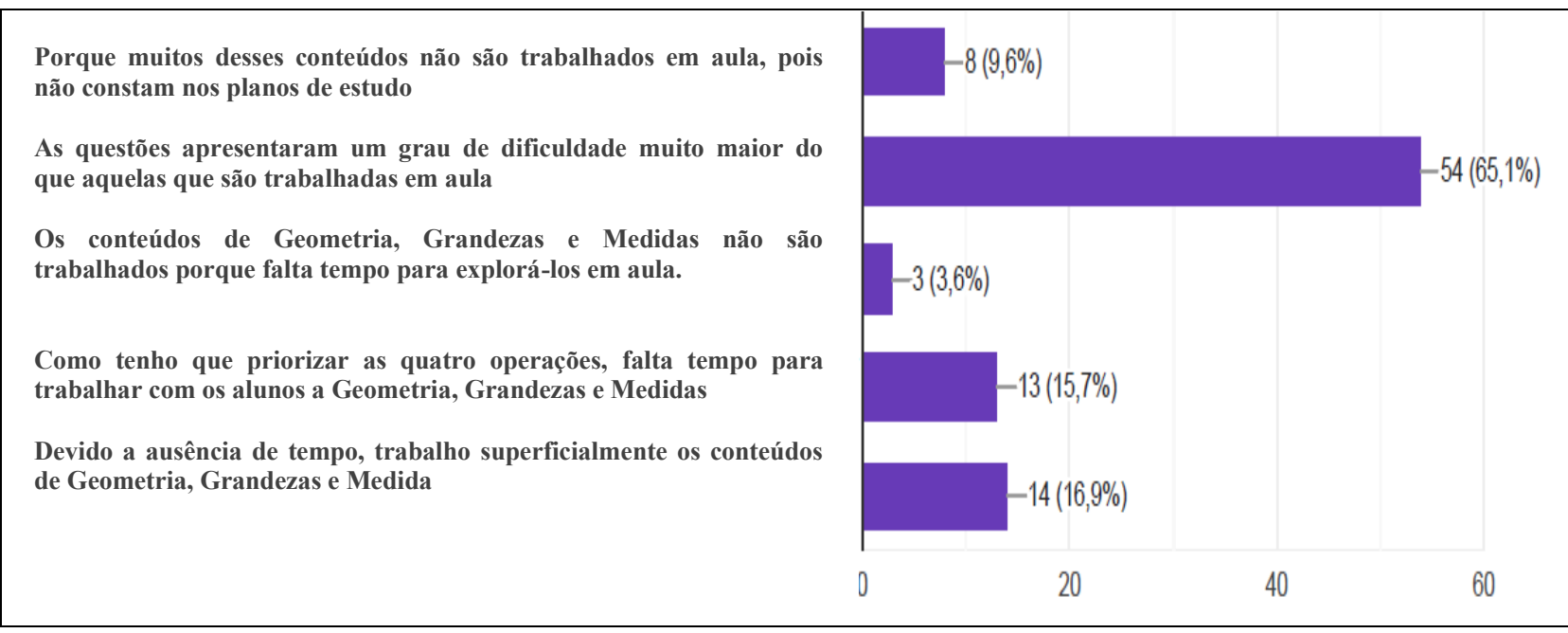

Figura 5: Motivos apontados pelos educadores sobre as dificuldades de resolução Fonte: A pesquisa

Para mais de $50 \%$ dos professores, as questões apresentaram um grau de dificuldade superior das que são trabalhadas em aula. Conforme Victor (2013), fazer o aluno gostar de estudar Matemática deve ser uma tarefa desafiadora para o professor e criar instrumentos incentivadores para esse jovem competir numa Olimpíada de Matemática deve ser uma preocupação presente nessa tarefa.

Para os alunos obterem sucesso em um desafio matemático é necessário que tenha motivos para buscar soluções. Sendo assim, o desafio só se concretiza se os objetos e os motivos convergirem para um mesmo propósito (resolução), dando-se isso num contexto social determinado.

As competições escolares como as Olimpíadas de Matemática, são propostas pedagógicas que desafiam e acabam provocando autonomia, desenvolvimento intelectual, inspiração ao trabalho em equipe e aprofundamento do conhecimento matemático.

Alves (2010), ao analisar como a OBMEP pode estimular e promover o estudo da Matemática entre os alunos de escolas públicas e que contribuições a OBMEP oferece para a melhoria da qualidade do ensino da Matemática na Educação Básica, identificou que a desmotivação dos alunos em participar das provas da OBMEP se deve à falta de informações e à ineficiente divulgação.

Conforme Cedro (2008), os alunos não nasceram com o objetivo de querer aprender, mas necessitam ser mobilizados para que isto ocorra. No relatório de Avaliação 
do impacto da OBMEP 2010, o principal foco da OBMEP era provocar o interesse e a motivação de alunos e de professores pela matemática e também o estímulo ao desenvolvimento e à melhoria do desempenho do aluno na disciplina de Matemática. (BRASIL, 2011). O desenvolvimento pessoal, o sucesso, o bem-estar servem como motivos para o aluno aprender e eles podem ser explorados pela OBMEP, que os estimula por meio de suas premiações.

Para Cocco (2014) como as provas da OBMEP abordam os diversos conteúdos de matemática, principalmente em forma de problemas, as questões exigem dos estudantes criatividade na sua resolução. A autora destaca que as escolas devem estar preparadas a fim de alcançar resultados satisfatórios na olimpíada.

Segundo Dante (1998), a resolução de problemas pode não ser uma tarefa fácil para os professores, pois se o estudante estiver acostumado a resolver apenas algoritmos, sentirá dificuldade de interpretar questões contextualizadas que envolvem um ou mais desses algoritmos. Isso ocorrerá, quando não forem trabalhadas previamente questões desse tipo, tornando-se trabalhoso/difícil para o educador alcançar bons resultados quanto à aprendizagem dos alunos no dia a dia escolar.

As Olimpíadas apresentam um banco de questões que pode ser utilizado em oportunidades que antecedem a Olimpíada. Conforme Biondi, Vasconcelos e Menezes (2007) é possível que esse recurso possa trazer melhorias no desempenho dos alunos nas avaliações da OBMEP porque apresenta formato semelhante à avaliação, contribuindo para o sucesso dos estudantes. Porém, de acordo com os autores, é perceptível uma dificuldade de comunicação entre a escola e a organização da Olimpíada, pois nem sempre a escola está informada sobre a existência desse instrumento para aprendizagem e, consequentemente, o estudante não o utiliza em sala de aula juntamente com os professores e, muito menos, fora do espaço escolar.

É importante que esteja em mente de todos os envolvidos no processo (organizadores, secretarias de educação, gestores e professores) o caráter pedagógico das Olimpíadas. Por isso, se faz necessário o planejamento, a elaboração, a divulgação, a aplicação e a premiação de ações desse cunho. Um exemplo, é o trabalho com o Banco de questões citado anteriormente, que poderá trazer uma ampliação de conhecimentos, por meio da construção de novos conceitos e despertar o interesse e a motivação para a Olimpíada.

Os professores também apontaram as unidades temáticas de maior dificuldade de trabalho em sala de aula. Elas estão indicadas na Figura 06. 


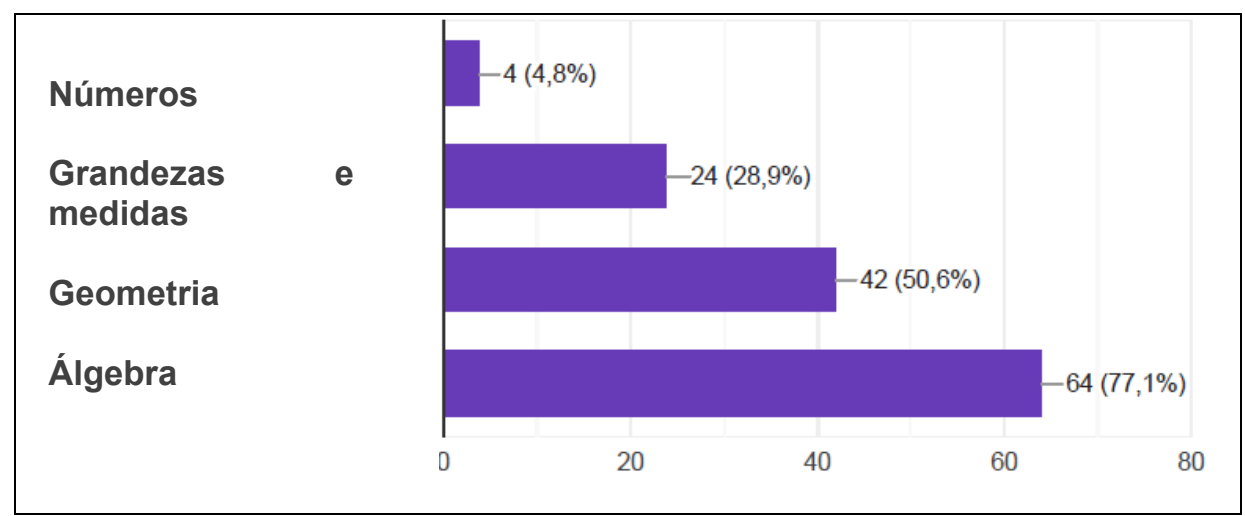

Figura 6: As unidades temáticas com mais dificuldades de se trabalhar com os alunos em aula Fonte: A pesquisa

Quando questionados sobre as justificativas para essa dificuldade, foram indicados pelos educadores os principais motivos (Figura 07).

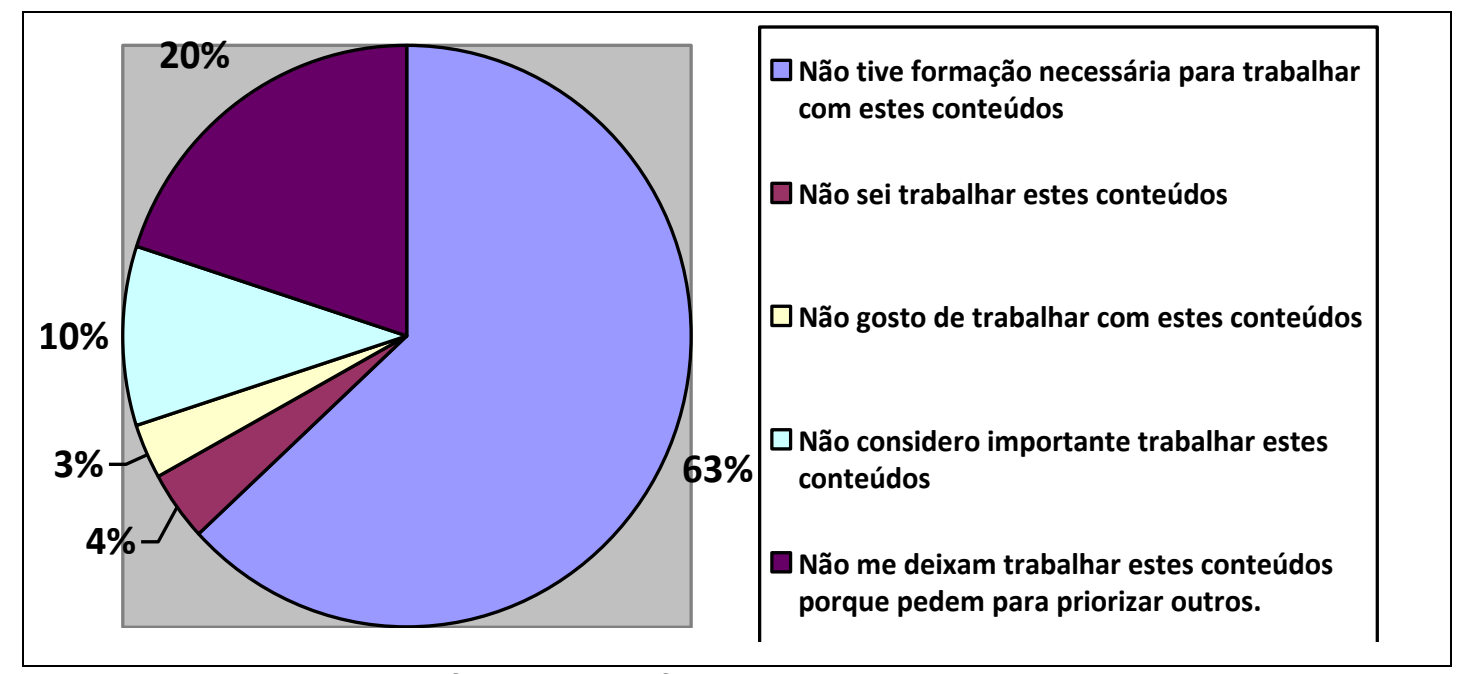

Figura 7: Justificativa das dificuldades de trabalho em sala de aula

Fonte: A pesquisa

De acordo com os resultados, observa-se que metade dos professores entrevistados apresentam dificuldade de trabalho em sala de aula com questões de Geometria e, aproximadamente, $80 \%$ com questões de álgebra. De forma expressiva $(20 \%)$, os professores destacam que nas escolas não deixam trabalhar esses conteúdos, porque pedem para priorizar as quatro operações, $10 \%$ não consideram importante trabalhar esses conteúdo, 3\% não gostam de trabalhar esses conteúdos e 4\% não sabem trabalhar esses conteúdos.

Para Zabala (1998) é importante considerar que 
a elaboração do conhecimento exige o envolvimento pessoal, o tempo e o esforço dos alunos, assim como a ajuda especializada, estímulos e afeto por parte dos professores e dos demais colegas. Ajuda pedagógica ao processo de crescimento e construção do aluno para incentivar os progressos que experimenta e superar os obstáculos que encontra. Ajuda necessária, porque sem ela os alunos por si sós dificilmente conseguiriam aprender o mais significativamente possível (1998,p.97).

Para Bachelard (1996, p. 18) "aquilo que cremos saber com clareza ofusca o que deveríamos saber", logo é necessário ir além do pensamento de que sabemos tudo e buscar mais conhecimentos. O desafio é então problematizar e, talvez, desconstruir o olhar do professor no sentido de que já se sabe tudo, é preciso ir além, pois a formação não se esgota na graduação. É preciso mudar a

[...] a forma pela qual se costuma conceber a aprendizagem das crianças a partir da própria perspectiva do adulto que já domina o conteúdo que quer ensinar. Dessa forma, não é possível compreender o ponto de vista do aprendiz, pois não se pode "enxergar" o objeto de seu conhecimento com os olhos de quem ainda não sabe (Weisz, 2001, p. 19).

De acordo com a pesquisa, para $63 \%$ dos professores a formação não lhes deu subsídios necessários para um trabalho com as unidades temáticas apontadas com dificuldades de trabalho. Para Lins (2005), o centro da atividade profissional do professor, é estar atento aos alunos, realizar leituras a respeito, tomar decisões sobre o que está acontecendo e definir o caminho a seguir. Portanto, conforme Skovsmose (2001), pensar a formação docente a partir desse paradigma é propiciar o desenvolvimento de um profissional politicamente crítico, ou seja, aquele que condiciona suas decisões de sala de aula aos seus pressupostos teórico-epistemológicos, assumindo dessa maneira autonomia crítica em sua formação profissional.

Para Nacarato (2011, p. 38),

[...] no que diz respeito à formação inicial, o desafio consiste em criar contextos em que as crenças que essas futuras (ou já) professoras foram construindo durante a sua escolarização possam ser problematizadas e colocadas em reflexão, mas, ao mesmo tempo, que possam tomar contato com os fundamentos da matemática de forma integrada às questões pedagógicas, dentro das atuais tendências em educação matemática.

Conforme Zuffi e Onuchic (2007), o trabalho com questões da olimpíada voltadas à problemas, leva os professores a mudarem suas práticas metodológicas, trabalhando com seus alunos questões relacionadas ao dia a dia. Portanto, a OBMEP pode contribuir para mudanças nas estratégias de ensino de matemática na medida em que se utiliza da resolução de problemas como estratégia de avaliação dos conhecimentos em matemática, inclusive de outras áreas do conhecimento. 
Acreditamos, também, que a introdução da resolução de problemas como uma metodologia, no sentido que aqui expressamos para a área de Matemática, possa colaborar para que haja alguma mudança na perspectiva da ação docente, para além da organização do conhecimento em disciplinas. Pode-se dizer que esta intervenção é modesta, pois a organização da escola escolhida permanece pautada no modelo disciplinar. No entanto, com a aplicação reiterada desta metodologia, esperamos que os alunos sejam estimulados a relacionar os conhecimentos escolares adquiridos, não só à resolução de problemas matemáticos e suas generalizações, mas também com problemas relativos a outras áreas do conhecimento e outras disciplinas escolares. (Zuffi; Onuchic, 2007, p. 85).

Logo, conforme Sá (2009), a contextualização dos conteúdos de uma olimpíada, por meio de assuntos interessantes, presentes nas notícias que os alunos têm contato em seu cotidiano, como filmes, etc., pode influenciar os alunos no interesse pela Matemática ou outras disciplinas envolvidas. Os alunos podem identificar na olimpíada, uma oportunidade de aprender conteúdos presentes no ambiente não formal de sala de aula.

É necessário encontrar alguma forma ou recurso que estimule a curiosidade dos estudantes e os incentive a realizar as avaliações. Mas, para isso, essas ações necessitam fazer sentido e ter objetivos bem definidos pelo professor na utilização desse recurso em sala de aula.

\section{CONSIDERAÇÕES FINAIS}

Espera-se que as considerações desse artigo não se tornem limitantes e sim estimulem novos estudos e pesquisas relacionadas à discussão das Olimpíadas de Matemática, pois ainda são necessárias novas análises relacionadas ao tema.

As olimpíadas de Matemática podem contribuir para mudanças nas estratégias de ensino dos professores, levando-os a repensar seus métodos e formas de construções de conceitos.

Observa-se, de uma forma geral, que as questões utilizadas nestes instrumentos, contextualizam os conceitos matemáticos, possibilitando que os estudantes identifiquem na olimpíada, uma oportunidade de construírem conteúdos presentes no ambiente não formal de sala de aula.

Portanto, as Olimpíadas podem fazer parte do processo de ensino-aprendizagem da matemática incentivando e motivando os estudantes a terem gosto pela disciplina. É também, uma ótima oportunidade, através dela, de utilizarmos a Resolução de problemas para se construir conceitos matemáticos e relacioná-los com situações do dia a dia. 


\section{REFERÊNCIAS}

Alves, W. J. S. (2010). O impacto da Olimpíada de Matemática em alunos da escola pública. (Dissertação Mestrado em Ensino de Matemática). Pontifícia Universidade Católica de São Paulo, São Paulo.

Bachelard, G. A. (1996). Formação do Espírito Científico: contribuição para uma psicanálise do conhecimento. Rio de Janeiro: Editora Contraponto.

Biondi, R. L., Vasconcellos, L., \& Menezes-Filho, N. A. (2009). Avaliando o impacto da Olimpíada Brasileira de Matemática das Escolas Públicas (OBMEP) no desempenho de matemática nas avaliações educacionais. In Anais. Rio de Janeiro: Sociedade Brasileira de Econometria. Recuperado de http://bibliotecadigital.fgv.br/ocs/index.php/sbe/EBE09/paper/view/1092/315.

Burigo, E. Z. (1989). Movimento da Matemática Moderna no Brasil: Estudo da Ação e do Pensamento de Educadores Matemáticos nos Anos 60. (Dissertação de Mestrado). Universidade Federal do Rio Grande do Sul, Porto Alegre.

Cedro, W.L. (2008). O motivo e a atividade do professor de Matemática uma perspectiva histórico-cultural. (Tese de Doutorado em Educação). Faculdade de Educação, USP, São Paulo.

Cocco, E. M.. (2013). OBMEP e avaliação em larga escala no município de Frederico Westphalen: discussões e encaminhamentos. (Dissertação de mestrado). Universidade Regional Integrada do Alto Uruguai, Frederico Westphalen.

DANTE, L.R. (1998). Didática da Resolução de Problemas de Matemática. 2. ed. São Paulo:Ática.

Lins, R. C. (2004). Matemática, monstros, significados e educação matemática. In: Bicudo, M.A.V.; Borba, M. C. B. (Orgs.). (2004), Educação matemática: pesquisa em movimento. (pp. 92-120). São Paulo: Cortez.

Maciel, M. M. G. (2008). A criação de um grupo de estudos segundo Fundamentos da Educação da Matemática Crítica: uma proposta de Educação Inclusiva. (Dissertação de Mestrado em Educação Matemática). Universidade Federal do Rio Grande do Sul, Porto Alegre.

Moreira, H., \& Caleffe, L. G. (2008). Metodologia da pesquisa para o professor pesquisador. 2. ed., Rio de Janeiro: Lamparina.

Nacarato, A. M.; Mengali, B. L. da S.; Passos, C. L. B. (2009). A matemática nos anos iniciais do ensino fundamental: Tecendo fios do ensinar e do aprender. Belo Horizonte: Autêntica.

OBMEP. Banco de Questões. Disponível em: < http://www.obmep.org.br/banco.htm>. Acesso em: 05 de maio de 2014. 
Pavanello, R. M.; Lopes, S. E.; Araujo, N. S. R. (2011). Leitura e interpretação de enunciados de problemas escolares de matemática por alunos do ensino fundamental regular e educação de jovens e adultos (EJA). Educar em Revista, 27, 126-140. dói:https://doi.org/10.1590/S0104-40602011000400009

Sá, K. K. (2009). A Olimpíada Brasileira de Física em Goiás Enquanto Ferramenta para a Alfabetização Científica: Tradução de Uma Educação não Formal. (Dissertação de Mestrado). Universidade Federal de Goiás, Goiás.

Sudbrack, E. M.; Cocco, E. M. (2013). Olimpíada de Matemática das escolas públicas e avaliação em larga escala: contribuições à qualidade educativa. Pleiade , v. 12, 55-71.

Turner, N. D. (1985) A historical sketch of olympiads: U.s.a. and international. College Mathematics Journal, v. 16, 330-335.

Weisz, T. \& Sanchez, A. (2002). O diálogo entre o ensino e a aprendizagem. São Paulo: Ática.

Zabala, A. (1998). A prática educativa: como ensinar. Porto Alegre: Editora Artes Médicas Sul Ltda.

Zuffi, E. M.; Onuchic, L. R. (2007) O Ensino-Aprendizagem de Matemática Através da Resolução de Problemas e os Processos Cognitivos Superiores. Unión-Revista Iberoamericana de educação Matemática, V. 11, 79-97.

\section{NOTAS}

\section{TÍTULO DA OBRA}

Primeira olimpíada brasileira de matemática dos anos iniciais - OBMEP: uma análise dos resultados obtidos pelos alunos e das percepções dos professores sobre o instrumento aplicado

Cláudio Cristiano Liell

Pós Doutor em Ensino de Ciências e Matemática

Faculdade Anhanguera Caxias do Sul, Professor adjunto, Caxias do Sul, RS, Brasil

cristianoliell@hotmail.com

Dhttp://orcid.org/0000-0003-1848-7569

\section{Arno Bayer}

Doutor em Ciências da Educação

Universidade Luterana do Brasil, Professor titular do Programa de Pós-Graduação em Ensino de Ciências e Matemática, Canoas, RS, Brasil

bayerarno@yahoo.com.br

Dhttp://orcid.org/0000-0001-7721-1162

Endereço de correspondência do principal autor

Rua Antônio Prado,161, 95760-000, São Sebastião do Caí, Rs, Brasil.

\section{AGRADECIMENTOS}

Aos professores partícipes da pesquisa.

\section{CONTRIBUIÇÃO DE AUTORIA}

Concepção e elaboração do manuscrito: C.C.Liell, A.Bayer

Coleta de dados: C.C.Liell, A.Bayer

Análise de dados: C.C.Liell, A.Bayer

Discussão dos resultados: C.C.Liell, A.Bayer

Revisão e aprovação: C.C.Liell, A.Bayer 
CONJUNTO DE DADOS DE PESQUISA

Todo o conjunto de dados que dá suporte aos resultados deste estudo foi publicado no próprio artigo.

\section{FINANCIAMENTO}

Não se aplica.

CONSENTIMENTO DE USO DE IMAGEM

Não se aplica.

\section{APROVAÇÃO DE COMITÊ DE ÉTICA EM PESQUISA}

Não se aplica.

\section{CONFLITO DE INTERESSES}

Não se aplica.

\section{LICENÇA DE USO}

Os autores cedem à Revemat os direitos exclusivos de primeira publicação, com o trabalho simultaneamente licenciado sob a Licença Creative Commons Attribution (CC BY) 4.0 International. Estra licença permite que terceiros remixem, adaptem e criem a partir do trabalho publicado, atribuindo o devido crédito de autoria e publicação inicial neste periódico. Os autores têm autorização para assumir contratos adicionais separadamente, para distribuição não exclusiva da versão do trabalho publicada neste periódico (ex.: publicar em repositório institucional, em site pessoal, publicar uma tradução, ou como capítulo de livro), com reconhecimento de autoria e publicação inicial neste periódico.

\section{PUBLISHER}

Universidade Federal de Santa Catarina. Grupo de Pesquisa em Epistemologia e Ensino de Matemática (GPEEM). Publicação no Portal de Periódicos UFSC. As ideias expressadas neste artigo são de responsabilidade de seus autores, não representando, necessariamente, a opinião dos editores ou da universidade.

\section{EDITOR}

Méricles Thadeu Moretti e Rosilene Beatriz Machado.

HISTÓRICO - uso exclusivo da revista

Recebido em: 09-07-2019 - Aprovado em: 20-07-2020 